\title{
Glycemic Control after Total Pancreatectomy for Intraductal Papillary Mucinous Neoplasm: An Exploratory Study
}

\author{
Laith H. Jamil, ${ }^{1}$ Ana M. Chindris, ${ }^{2}$ Kanwar R. S. Gill, ${ }^{1}$ Daniela Scimeca, ${ }^{1}$ \\ John A. Stauffer, ${ }^{3}$ Michael G. Heckman, ${ }^{4}$ Shon E. Meek, ${ }^{2}$ Justin H. Nguyen, ${ }^{5}$ \\ Horacio J. Asbun, ${ }^{3}$ Massimo Raimondo, ${ }^{1}$ Timothy A. Woodward, ${ }^{1}$ and Michael B. Wallace ${ }^{1}$
}

${ }^{1}$ Division of Gastroenterology and Hepatology, Mayo Clinic, Jacksonville, FL 32224, USA

${ }^{2}$ Division of Endocrinology, Mayo Clinic, Jacksonville, FL 32224, USA

${ }^{3}$ Department of Surgery, Mayo Clinic, Jacksonville, FL 32224, USA

${ }^{4}$ Biostatistics Unit, Mayo Clinic, Jacksonville, FL 32224, USA

${ }^{5}$ Department of Transplantation, Mayo Clinic, Jacksonville, FL 32224, USA

Correspondence should be addressed to Michael B. Wallace, wallace.michael@mayo.edu

Received 30 April 2012; Accepted 3 July 2012

Academic Editor: Christos G. Dervenis

Copyright () 2012 Laith H. Jamil et al. This is an open access article distributed under the Creative Commons Attribution License, which permits unrestricted use, distribution, and reproduction in any medium, provided the original work is properly cited.

Background. Glycemic control following total pancreatectomy (TP) has been thought to be difficult to manage. Diffuse intraductal papillary mucinous neoplasm (IPMN) is a potentially curable precursor to pancreatic adenocarcinoma, best treated by TP. Objective. Compare glycemic control in patients undergoing TP for IPMN to patients with type 1 diabetes mellitus (DM). Design/Setting. Retrospective cohort. Outcome Measure. Hemoglobin A1C(HbA1C) at 6, 12, 18, and 24 months after TP. In the control group, baseline was defined as 6 months prior to the first HbAlc measure. Results. Mean HgbA1C at each point of interest was similar between TP and type I DM patients ( 6 months (7.5\% versus $7.7 \%, P=0.52), 12$ months $(7.3 \%$ versus $8.0 \%, P=0.081)$, 18 months $(7.7 \%$ and $7.6 \%, P=0.64)$, and at 24 months $(7.3 \%$ versus $7.8 \%, P=0.10))$. Seven TP patients $(50 \%)$ experienced a hypoglycemic event compared to 65 type $1 \mathrm{DM}$ patients $(65 \%, P=0.38)$. Limitations. Small number of TP patients, retrospective design, lack of long-termfollowup. Conclusion. This suggests that glycemic control following TP for IPMNcan be well managed, similar to type 1 DM patients. Fear of DM following TP for IPMN should not preclude surgery when TP is indicated.

\section{Introduction}

Diabetes mellitus (DM) induced by total pancreatectomy (TP), often termed "Pancreatogenic Diabetes," is often thought to be difficult to manage [1-4]. The notion that TP could cause brittle diabetes in up to $25 \%$ of patients may adversely influence the decision to perform the surgery. In addition, the overall quality of life will likely be affected by such intervention [5]. More recent data suggests that glycemic control following TP may not be as challenging as initially thought [6]. Intraductal papillary mucinous neoplasm (IPMN) is a distinct pathological entity comprised of a papillary proliferation of mucin-producing epithelial cells that may produce excessive mucus and may cause cystic dilation of the pancreatic duct [7]. IPMN has a broad histological spectrum, ranging from minimal mucinous hyperplasia or adenoma to invasive carcinoma [8]. Criteria for pancreatic resections in IPMN, including TP, have been proposed [9]. IPMN involvement of the main pancreatic duct has been shown to be a risk factor for prevalent and incident cancers and therefore is a leading cause for recommending surgical resection [8]. Recent evidence reports that TP for IPMN is gaining popularity [10-14].

Many published studies evaluating glycemic control post-TP have included all patients undergoing TP regardless of etiology [5,6]. Blanchet et al. reported a series of 10 patients in which glycemic control was achieved successfully after TP for mucinous pancreatic tumors; seven of those patients had IPMN [15].

It is unknown whether the underlying pancreatic disease has any impact on insulin production prior to $\mathrm{TP}$, which may affect glycemic control after surgery. 
Most studies evaluating glycemic control in these patients were performed prior to the availability of more advanced treatment modalities of DM such as insulin pumps [1-5].

The aim of this exploratory study was to evaluate glycemic control in patients undergoing TP for IPMN and compare them to a control group of patients with type $1 \mathrm{DM}$, who were being followed during the same period. This included both long-term control, through measuring HbAlc, as well as occurrence of reported glycemic controlrelated complications such as hypoglycemia and hyperglycemia. We also evaluated the outcome of these reported episodes. This data stemmed and was expanded from a previously published study where we examined the outcome of TP for various indications [16].

\section{Methods}

We performed a retrospective chart review of all patients who underwent TP for IPMN between July 2004 and July 2008 at Mayo Clinic, in Jacksonville, Florida. We identified 29 patients. Follow-up data was available in 19 patients. Patients were included if they had at least one HbAlc measurement at any of the 4 time points of interest $(6[ \pm 3], 12[ \pm 3], 18[ \pm 3]$, or $24[ \pm 3]$ months after TP). Such data was available for 14 of the 29 patients (48\%). Sample sizes at each of the four time points were $N=10, N=9, N=7$, and $N=6$, respectively. The date of TP was considered as the baseline time point in TP patients. Of the 14 patients included in this study, 2 had type $2 \mathrm{DM}$ prior to surgery. When comparing the 14 included TP patients with the 15 patients who were excluded due to insufficient data, no significant difference regarding age at surgery, gender, weight, BMI, pancreatic enzyme supplement use, or insulin regimen was noted (all $P \geq 0.11$ ).

Type I DM patients were included if at baseline, which was defined as 6 months prior to the first $\mathrm{HbAlc}$ measure, their duration of disease was at least 2 years. $\mathrm{HbAlc}$ measures in controls were considered at the same four time points as the TP patients $(6[ \pm 3], 12[ \pm 3], 18[ \pm 3]$, or $24[ \pm 3]$ months after baseline). We identified 366 patients with an ICD code corresponding to type 1 diabetes mellitus (medical record numbers in arithmetical order) from our outpatient clinic. We selected every 5th patient on the list; after that, we continued with every 5 th patient from the remaining list and so on until we identified 100 patients that we used as controls. Patients who were found to have type $2 \mathrm{DM}$ during chart review were excluded. These patients were treated in our clinic within the same timeframe as the IPMN patients, between July 2003 and July 2006 and therefore had access to the same therapeutic means as our patient population. All patients had HbA1C measured within the interval studied.

2.1. Total Pancreatectomy Insulin Regimens and Doses. All patients were started on an insulin infusion following surgery and were discharged on meal time insulin Aspart (Novo Nordisk, Bagsvaerd, DN) with a correction scale. In addition, patients were given either Recombinant Insulin Glargine (Sanofi-Aventis, Bridgewater, N.J.) (13 patients) or Insulin Detemir (Novo Nordisk, Bagsvaerd, DN) (one patient), based on the preference of their endocrinologist. Their most current insulin regimens were Recombinant Insulin Glargine2-24 units once a day along with Insulin Aspart per sliding scale for meal coverage in 10 patients, Insulin pump in 3 patients, and Insulin Detemir12 units in the morning and four units in the evening along with Insulin Aspart per sliding scale for meal coverage in 1 patient.

2.2. Statistical Analysis. Patient characteristics at baseline were compared between TP patients and type I DM patients using a Wilcoxon rank-sum test or Fisher's exact test. In the primary analysis, we compared mean $\mathrm{HbAlc}$ values between TP patients and type I DM patients using a two-sample $t$-test separately at each time point. We also estimated the difference in mean $\mathrm{HbAlc}$ between groups along with a $95 \%$ confidence interval (CI). Additionally, we examined the sensitivity of the results to the adjustment for potentially confounding variables in multivariable linear regression analysis, adjusting for any variable that differed significantly $(P \leq 0.05)$ between TP patients and type I DM patients. In secondary analysis, again separately at each time point, we estimated the proportion of patients with a HbAlc level of less than 7\% for TP patients and type I diabetes patients using exact binomial 95\% CI and compared these proportions using Fisher's exact test. We estimated the difference in this proportion between groups along with a $95 \%$ small sample CI using Newcombe's score method [17]. No adjustment for potentially confounding variables was made in this secondary analysis, owing to the limitations on the number of variables that can be reasonably adjusted for in a regression model involving a dichotomous outcome as opposed to a continuous outcome [18]. We also evaluated trends in HbAlc values over time, separately in TP and type I DM patients, using mixed effects linear regression models including a random effect for patient. $P$-values less than or equal to 0.05 were considered statistically significant. All statistical analyses were performed using SPLUS (version 8.0.1; Insightful Corporation, Seattle, Washington).

\section{Results}

3.1. Patient Characteristics. Patient characteristics at baseline for TP and type I DM patients are shown in Table 1. TP patients were older (median: 72 years versus 52 years, $P<$ $0.001)$, while the control group had more men (52\% versus $14 \%, P=0.01$ ), more years of education (median: 16 years versus 12 years, $P=0.034$ ), and were heavier at baseline (median: $78 \mathrm{~kg}$ versus $60 \mathrm{~kg}, P=0.028$ ) when compared to type I DM patients. BMI was not significantly different between the two groups (median: 26 versus $24, P=0.47$ ). The median duration of disease in type I DM patients was 26 years (range: 2 years- 55 years). The indication for TP was diffuse involvement of the pancreas in 11 patients and positive margins during surgery in the remaining three patients. On pathology, mucinous adenocarcinoma was noted in one patient, noninvasive carcinoma in eight patients, adenoma in four patients, and one patient had borderline findings for malignancy. None had lymphovascular invasion. There was 
TABLe 1: Patient characteristics at baseline.

\begin{tabular}{lccc}
\hline Variable & TP $(N=14)$ & Type I DM $(N=100)$ & $P$ value \\
\hline Age at baseline (years) & $72(57-78)$ & $52(21-84)$ & \\
Gender & & $52(52 \%)$ \\
$\quad$ Male & $2(14 \%)$ & $48(48 \%)$ & 0.010 \\
$\quad$ Female & $12(86 \%)$ & $78(49-130)$ & $26(20-40)$ \\
Weight at baseline $(\mathrm{kg})$ & $60(50-105)$ & $16(8-18)$ & 0.028 \\
BMI at baseline & $24(20-36)$ & N/A & 0.47 \\
Years of education & $12(12-17)$ & $26(2-55)$ & N/A \\
Pancreatic enzyme supplement & $13(93 \%)$ & N/A \\
Duration of disease (years) & N/A &
\end{tabular}

The sample median (minimum-maximum) is given for numerical variables. Information was unavailable for years of education $(N=9)$. $P$-values result from a Wilcoxon rank sum test or Fisher's exact test. (TP: total pancreatectomy; DM: diabetes mellitus).

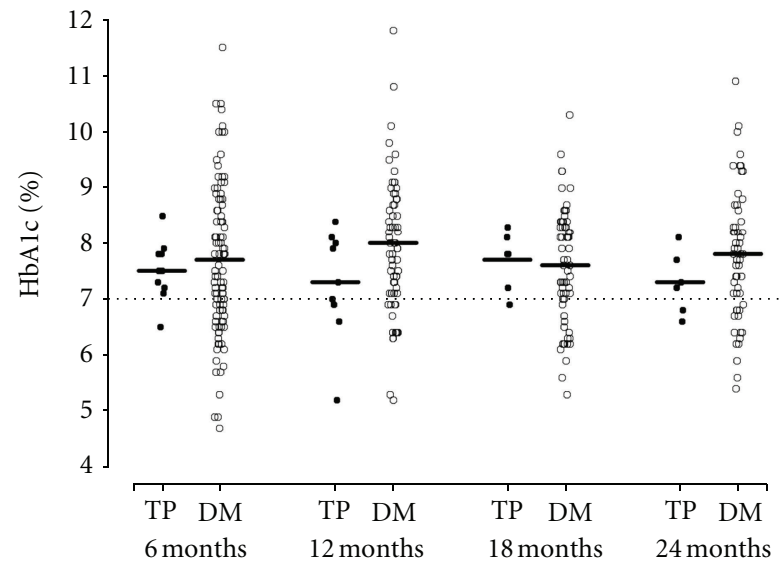

Figure 1: HbA1c values after baseline in TP and type I diabetes mellitus patients. The sample mean is shown with a solid horizontal line.

no recurrence of disease noted in these patients during their followup.

3.2. Glycemic Control. Mean HbAlc was similar between TP and type I DM patients at six months $(7.5 \%$ versus $7.7 \%$, $P=0.74), 12$ months $(7.3 \%$ versus $8.0 \%, P=0.11), 18$ months $(7.7 \%$ and $7.6 \%, P=0.79)$, and at 24 months $(7.3 \%$ versus $7.8 \%, P=0.31$ ) (Table 2 ). These findings remained consistent when adjusted for age at baseline, gender, weight at baseline, and years of education (Table 2), all of which differed significantly between groups. There was no evidence of a difference in HbA1c values between the 6-month, 12month, 18-month, and 24-month time points in TP patients $(P=0.37)$ or type I DM patients $(P=0.46)$.

Differences in the proportion of patients with an $\mathrm{HbAlc}$ less than $7 \%$ at each time point of interest after baseline were also not significant (all $P \geq 0.42$ ) between TP and control patients (10\% versus $33 \%$ at 6 months, $33 \%$ versus $21 \%$ at 12 months, $14 \%$ versus $25 \%$ at 18 months, and $33 \%$ versus $28 \%$ at 24 months) (Table 3 ). The individual HbAlc values for TP patients and controls for the different time periods are shown in Figure 1.
3.3. Glycemic Control-Related Complications. When considering the presence of a symptomatic hypoglycemic event at any point during the study period after baseline, seven $\mathrm{TP}$ patients $(50 \%)$ experienced a hypoglycemic episode compared to 65 type I DM patients $(65 \%)(P=0.38)$. Six out of seven TP patients $(86 \%)$ who experienced a hypoglycemic episode treated the episode themselves at home, compared to 59 type I DM patients (91\%). The remaining 6 type I DM patients (9\%) received treatment at a hospital compared to $1 \mathrm{TP}$ patient who required admission to the emergency room, where she was treated with intravenous Dextrose 50\% and discharged home. No patient reported a hyperglycemic episode that required hospitalization or evaluation in the emergency department.

3.4. Pancreatic Insufficiency. Following hospital discharge, 13 of 14 TP patients continued on pancreatic enzyme supplements to avoid malabsorption, with its potential negative effects on glycemic control. Only two patients continued to complain of steatorrhea because of intolerance of medications (one patient) and inadequate dosing (one patient).

\section{Discussion}

The findings of our exploratory study suggest that glycemic control following TP may be manageable, with control and complication rates similar to that of typical type $1 \mathrm{DM}$ patients who have not undergone pancreatectomy. Our focus on IPMN patients offered a more homogenous patient population with a relatively reduced list of comorbidities that could influence the results.

The endocrine abnormalities accompanying TP include both glucagon and pancreatic polypeptide (PP) deficiency in addition to insulin and thus are considered to be different than conventional type 1 and type 2 DM. TP patients have been thought to be more vulnerable to severe hypoglycemic episodes, tend to be resistant to ketosis, and have a higher plasma level of gluconeogenic precursors, which include lactate and alanine because of glucagon absence $[19,20]$. As for pancreatic polypeptide, it has been suggested that it plays a key role in the induction of hepatic sensitivity to insulin and insulin receptor regulation $[21,22]$. Following TP, insulin 


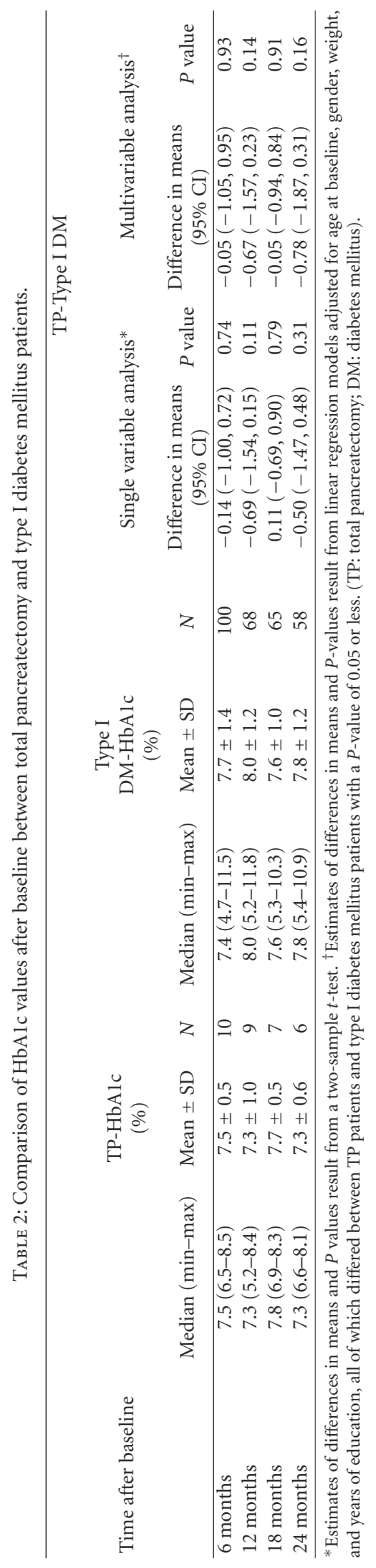


TABLE 3: Comparison of presence of $\mathrm{HbA1c}<7 \%$ after baseline between total pancreatectomy and type I diabetes mellitus patients.

\begin{tabular}{|c|c|c|c|c|c|c|}
\hline \multirow[b]{2}{*}{ Time after baseline } & \multicolumn{2}{|l|}{$\mathrm{TP}$} & \multicolumn{2}{|l|}{ Type I DM } & \multicolumn{2}{|l|}{ TP-Type I DM } \\
\hline & $\begin{array}{c}\text { Fraction }(\%) \text { with } \\
\text { HbAlc }<7 \%\end{array}$ & $95 \% \mathrm{CI}$ & $\begin{array}{c}\text { Fraction (\%) with } \\
\text { HbAlc }<7 \%\end{array}$ & $95 \% \mathrm{CI}$ & $\begin{array}{l}\text { Difference in proportions } \\
(95 \% \mathrm{CI})\end{array}$ & $P$ value \\
\hline 6 months & $1 / 10(10 \%)$ & $0 \%-45 \%$ & $33 / 100(33 \%)$ & $24 \%-43 \%$ & $-23 \%(-36 \%, 9 \%)$ & 0.17 \\
\hline 12 months & $3 / 9(33 \%)$ & $7 \%-70 \%$ & $14 / 68(21 \%)$ & $12 \%-32 \%$ & $13 \%(-11 \%, 45 \%)$ & 0.42 \\
\hline 18 months & $1 / 7(14 \%)$ & $0 \%-58 \%$ & $16 / 65(25 \%)$ & $15 \%-37 \%$ & $-10 \%(-27 \%, 28 \%)$ & 1.00 \\
\hline 24 months & $2 / 6(33 \%)$ & $4 \%-78 \%$ & $16 / 58(28 \%)$ & $17 \%-41 \%$ & $6 \%(-21 \%, 44 \%)$ & 1.00 \\
\hline
\end{tabular}

$P$-values result from Fisher's exact test. (TP: total pancreatectomy; DM: diabetes mellitus).

receptors are unregulated peripherally, rendering patients uniquely sensitive to insulin replacement [23], resulting in problematic glycemic control and increased susceptibility to both hyper- and hypoglycemia.

The underlying pancreatic disease may play a role in glycemic control subsequent to TP. Previous studies have shown that patients with chronic pancreatitis tended to have a poorer diabetic outcome [24]. There has been a recent increase in performing TP for malignant diseases of the pancreas [25], benign pancreatic disease [26], patients with genetic abnormalities [27] and premalignant pancreatic disease, mainly IPMN [10-14, 28]. More recent studies looking at outcome after TP show more favorable outcome with both quality of life $[5,29]$ and in glycemic control $[6,15]$. None of these studies focused on IPMN patients.

The improved overall results seen in the past decade may also be multifactorial. Improvements in glucose monitoring systems, insulin delivery systems, and insulin formulations may contribute to superior glycemic control for these patients [30].

Since the first description of IPMN in 1982 by Ohashi et al. [31], IPMN is being increasingly recognized in all parts of the world [32-37]. IPMN has a broad histological spectrum, ranging from minimal mucinous hyperplasia or adenoma to invasive carcinoma [12]. IPMNs are believed to have typical adenoma-carcinoma sequence. The estimated time for this progression is thought to be approximately 5 years [12]. However, it remains a difficult task to determine which IPMN may have malignancy based only on imaging characteristics. This has led to an international consensus on guidelines for management of IPMN including when surgery should be considered [9].

The frequency of malignancy (in situ and invasive) also varies, depending on the type of IPMN. In main duct IPMN, the frequency of malignancy ranges between 60 and $92 \%$, with a mean of $70 \%$. Approximately two-thirds of these malignant neoplasms are invasive [12, 37-44], while in branch duct IPMN, the frequency of malignancy is significantly less, ranging from 6 to $46 \%[12,38-44]$.

One of the main reasons to consider TP in IPMN patients is the increase in survival for those with pancreatic cancer arising in the background of IPMN versus sporadic pancreatic cancer after surgical resection [8]. Another reason is the increased survival in patients with noninvasive IPMN compared to those with invasive IPMN $[11,12,14,28,45$, 46 ], where it can be as low as $24 \%$ at 2.5 years [ 46$]$.
Recurrence of tumor after resection is not uncommon. In a study by Chari et al, $8 \%$ of noninvasive IPMNs recurred after partial pancreatectomy compared to none after TP [11]. Interestingly, recurrence was found to be noninvasive in three patients and invasive in two patients [11]. This is in sharp contrast to patients who had invasive IPMN, where recurrence rates after partial pancreatectomy were $67 \%$ and after TP were 62\% [11]. This emphasizes the need for early detection and aggressive therapy prior to the development of invasive cancer.

Islet cell autotransplants in patients undergoing TP for chronic pancreatitis have shown to have durable function and extended insulin-independence rates, despite a lower beta-cell mass [47]. The fear of infusion of occult carcinoma cells in the islet preparation has limited the use of this procedure for patients with pancreatic adenocarcinoma, although there have been a few published case reports [48, 49]. In one study, islet cell autotransplant was performed in two patients with IPMN, one who underwent TP, and another underwent partial pancreatectomy, in which IPMN was confined to the pancreatic body on imaging, with no evidence of recurrence at one-year followup [50]. IPMN may occur within or away from the intraductal component [51] thus the multicentric nature of IPMN raises a question concerning the suitability of islet cell autotransplantation as an option in the management of these tumors.

The HbAlc levels seen in our post-TP and control patients are comparable to published studies, including those seen in patients after TP $[5,6,29]$, in patients with type $1 \mathrm{DM}$ $[52,53]$, and to type 2 DM patients in the United Kingdom Prospective Diabetes Study (UKPDS) [54].

Hypoglycemia is a feared complication of pancreatogenic diabetes, due to the loss of the counterregulatory mechanism offered by glucagon. The percentage of hypoglycemic episodes in TP patients in our study was similar to that of type $1 \mathrm{DM}$ patients, and none required hospital admission.

Similar to the study by Jethwa et al. [6], we were unable to find specific reasons for why keeping diabetes under control in this group did not seem to be any more difficult than in patients with autoimmune type 1 diabetes. Better patient understanding of consequences of $\mathrm{TP}$, early education on diabetes (all patients were seen by an endocrinologist immediately following their operation), advances in medical therapy, and blood glucose monitoring could all be contributory factors. 
Although use of various types of insulin among patients within both groups made it impossible to make direct comparison, all regimens used were within current guidelines and had the potential to offer excellent glucose control.

Diabetes control is mainly patient driven. Excellent control has been achieved with various insulin regimens, including those used by the patients included in this study.

In addition to improved endocrine control, exocrine insufficiency may be improved by modern pancreatic enzyme formulations. This is important to avoid malabsorption, with its potential negative effects on glycemic control.

This study is not without its limitations. This is a retrospective study conducted at a single center. The length of followup was short; however, this study did not intend to assess long-term glycemic control and complications. Also, hypo- and hyperglycemia were self-reported and therefore, subject to recall bias.

The chief limitation of this study is the small sample size, particularly the small number of TP patients, which resulted in very low power to detect differences between the TP group and the type I DM patients. TP patients were included if they had $\mathrm{HbAlc}$ values available at any one of the four time points we considered, and thus our sample size of $14 \mathrm{TP}$ patients was further reduced at each given post-TP time point. Thus, the possibility of a type II error is important to acknowledge.

\section{Conclusion}

These findings suggest that glycemic control following TP for IPMN can be well managed and controlled with a variety of insulin therapy regimens. If these findings are validated in a prospective study that involves a larger number of TP patients, implications are that fear of DM following TP for IPMN should not preclude surgery.

\section{Study Highlights}

(1) What is the current knowledge.

Glycemic control following total pancreatectomy has been thought to be difficult to manage with potential life-threatening complications.

(2) What is new here.

(a) Glycemic control following total pancreatectomy for intraductal papillary mucinous neoplasm can be well managed and controlled with a variety of insulin therapy regimens.

(b) The mean HbAlc was similar between patient undergoing total pancreatectomy for intraductal papillary mucinous neoplasm and type I DM patients.

\section{References}

[1] T. Kiviluoto, T. Schroder, and S. L. Karonen, "Glycemic control and serum lipoproteins after total pancreatectomy," Annals of Clinical Research, vol. 17, no. 3, pp. 110-115, 1985.
[2] C. M. Dresler, J. G. Fortner, K. McDermott, and D. R. Bajorunas, "Metabolic consequences of (regional) total pancreatectomy," Annals of Surgery, vol. 214, no. 2, pp. 131-140, 1991.

[3] F. Duron and J. J. Duron, "Pancreatectomy and diabetes," Annales de Chirurgie, vol. 53, no. 5, pp. 406-411, 1999.

[4] A. Sauvanet, "Functional results of pancreatic surgery," Revue du Praticien, vol. 52, no. 14, pp. 1572-1575, 2002.

[5] B. J. Billings, J. D. Christein, W. S. Harmsen et al., "Qualityof-life after total pancreatectomy: is it really that bad on longterm follow-up?" Journal of Gastrointestinal Surgery, vol. 9, no. 8, pp. 1059-1067, 2005.

[6] P. Jethwa, M. Sodergren, A. Lala et al., "Diabetic control after total pancreatectomy," Digestive and Liver Disease, vol. 38, no. 6, pp. 415-419, 2006.

[7] G. Kloppel, D. Longnecker, C. Capella, and L. Sobin, Histological Typing of Tumors of the Exocrine Pancreas, World Health Organization International, 2nd edition, 1996.

[8] T. A. Sohn, C. J. Yeo, J. L. Cameron, C. A. IacobuzioDonahue, R. H. Hruban, and K. D. Lillemoe, "Intraductal papillary mucinous neoplasms of the pancreas: an increasingly recognized clinicopathologic entity," Annals of Surgery, vol. 234, no. 3, pp. 313-322, 2001.

[9] M. Tanaka, S. Chari, V. Adsay et al., "International consensus guidelines for management of intraductal papillary mucinous neoplasms and mucinous cystic neoplasms of the pancreas," Pancreatology, vol. 6, no. 1-2, pp. 17-32, 2006.

[10] J. Bendix Holme, N. O. Jacobsen, M. Rokkjaer, and A. Kruse, "Total pancreatectomy in six patients with intraductal papillary mucinous tumour of the pancreas: the treatment of choice," Journal of the International Hepato Pancreato Biliary, vol. 3, no. 4, pp. 257-262, 2001.

[11] S. T. Chari, D. Yadav, T. C. Smyrk et al., "Study of recurrence after surgical resection of intraductal papillary mucinous neoplasm of the pancreas," Gastroenterology, vol. 123, no. 5, pp. 1500-1507, 2002.

[12] T. A. Sohn, C. J. Yeo, J. L. Cameron et al., "Intraductal papillary mucinous neoplasms of the pancreas: an updated experience," Annals of Surgery, vol. 239, no. 6, pp. 788-799, 2004.

[13] K. Yamaguchi, H. Konomi, K. Kobayashi et al., "Total pancreatectomy for intraductal papillary-mucinous tumor of the pancreas: reappraisal of total pancreatectomy," HepatoGastroenterology, vol. 52, no. 65, pp. 1585-1590, 2005.

[14] A. D. Yang, L. G. Melstrom, D. J. Bentrem et al., "Outcomes after pancreatectomy for intraductal papillary mucinous neoplasms of the pancreas: an institutional experience," Surgery, vol. 142, no. 4, pp. 529-537, 2007.

[15] M. C. Blanchet, F. Andreelli, J. Y. Scoazec et al., "Total pancreatectomy for mucin-producing tumor of the pancreas," Annales de Chirurgie, vol. 127, no. 6, pp. 439-448, 2002.

[16] J. A. Shtauffer, J. H. Nguyen, M. G. Heckman et al., "Patient outcomes after total pancreatectomy: a single centre contemporary experience," Journal of the International Hepato Pancreato Biliary, vol. 11, no. 6, pp. 483-492, 2009.

[17] R. G. Newcombe, "Interval estimation for the difference between independent proportions: comparison of eleven methods," Statistics in Medicine, vol. 17, no. 8, pp. 873-890, 1998.

[18] F. E. Harrell Jr., Regression Modeling Strategies: With Application to Linear Models, Logistic Regression, and Survival Analysis, 2001.

[19] R. H. Unger, "Glucagon physiology and pathophysiology," The New England Journal of Medicine, vol. 285, no. 8, pp. 443-449, 1971. 
[20] H. Karmann, F. Laurent, and P. Mialhe, "Pancreatic hormones disappearance after total pancreatectomy in the duck: correlation between plasma glucagon and glucose," Hormone and Metabolic Research, vol. 19, no. 11, pp. 538-541, 1987.

[21] N. E. Seymour, C. Brunicardi, R. L. Chaiken et al., "Reversal of abnormal glucose production after pancreatic resection by pancreatic polypeptide administration in man," Surgery, vol. 104, no. 2, pp. 119-129, 1988.

[22] L. A. Slezak and D. K. Andersen, "Pancreatic resection: effects on glucose metabolism," World Journal of Surgery, vol. 25, no. 4, pp. 452-460, 2001.

[23] R. Nosadini, S. Del Prato, A. Tiengo et al., "Insulin sensitivity, binding, and kinetics in pancreatogenic and type I diabetes," Diabetes, vol. 31, no. 4, part 1, pp. 346-355, 1982.

[24] F. P. Gall, C. Gebhardt, and H. Zirngibl, "Chronic pancreatitis, results in 116 consecutive partial duodenopancreatectomies combined with occlusion of the pancreatic duct," Fortschritte der Medizin, vol. 99, no. 47-48, pp. 1967-1972, 1981.

[25] H. Nathan, C. L. Wolfgang, B. H. Edil et al., "Peri-operative mortality and long-term survival after total pancreatectomy for pancreatic adenocarcinoma: a population-based perspective," Journal of Surgical Oncology, vol. 99, no. 2, pp. 87-92, 2009.

[26] G. Garcea, J. Weaver, J. Phillips et al., "Total pancreatectomy with and without islet cell transplantation for chronic pancreatitis: a series of 85 consecutive patients," Pancreas, vol. 38, no. 1, pp. 1-7, 2009.

[27] D. K. Bartsch, "Familial pancreatic cancer," British Journal of Surgery, vol. 90, no. 4, pp. 386-387, 2003.

[28] S. C. Kim, K. T. Park, Y. J. Lee et al., "Intraductal papillary mucinous neoplasm of the pancreas: clinical characteristics and treatment outcomes of 118 consecutive patients from a single center," Journal of Hepato-Biliary-Pancreatic Surgery, vol. 15, no. 2, pp. 183-188, 2008.

[29] M. W. Müller, H. Friess, J. Kleeff et al., "Is there still a role for total pancreatectomy?” Annals of Surgery, vol. 246, no. 6, pp. 966-974, 2007.

[30] D. G. Heidt, C. Burant, and D. M. Simeone, "Total pancreatectomy: indications, operative technique, and postoperative sequelae," Journal of Gastrointestinal Surgery, vol. 11, no. 2, pp. 209-216, 2007.

[31] K. Ohashi, Y. Murakami, and M. Maruyama, "Four cases of mucin producing cancer of the pancreas on specific findings of the papilla of Vater," Digestive Endoscopy, vol. 20, pp. 348351, 1982.

[32] Y. Itai, K. Ohhashi, and H. Nagai, "'Ductectatic' mucinous cystadenoma and cystadenocarcinoma of the pancreas," Radiology, vol. 161, no. 3, pp. 697-700, 1986.

[33] M. Yamada, S. Kozuka, K. Yamao, S. Nakazawa, Y. Naitoh, and Y. Tsukamoto, "Mucin-producing tumor of the pancreas," Cancer, vol. 68, no. 1, pp. 159-168, 1991.

[34] K. Yamaguchi, Y. Ogawa, K. Chljiiwa, and M. Tanaka, "Mucinhypersecreting tumors of the pancreas: assessing the grade of malignancy preoperatively," American Journal of Surgery, vol. 171, no. 4, pp. 427-431, 1996.

[35] E. V. Loftus Jr., B. A. Olivares-Pakzad, K. P. Batts et al., "Intraductal papillary-mucinous tumors of the pancreas: clinicopathologic features, outcome, and nomenclature," Gastroenterology, vol. 110, no. 6, pp. 1909-1918, 1996.

[36] M. Sugiyama, Y. Atomi, and J. Hachiya, "Intraductal papillary tumors of the pancreas: evaluation with magnetic resonance cholangiopancreatography," American Journal of Gastroenterology, vol. 93, no. 2, pp. 156-159, 1998.
[37] R. Salvia, C. Fernández-Del Castillo, C. Bassi et al., "Main-duct intraductal papillary mucinous neoplasms of the pancreas: clinical predictors of malignancy and long-term survival following resection," Annals of Surgery, vol. 239, no. 5, pp. 678687, 2004.

[38] M. Kobari, S. I. Egawa, K. Shibuya et al., "Intraductal papillary mucinous tumors of the pancreas comprise 2 clinical subtypes. Differences in clinical characteristics and surgical management," Archives of Surgery, vol. 134, no. 10, pp. 11311136, 1999.

[39] B. Terris, P. Ponsot, F. Paye et al., "Intraductal papillary mucinous tumors of the pancreas confined to secondary ducts show less aggressive pathologic features as compared with those involving the main pancreatic duct," American Journal of Surgical Pathology, vol. 24, no. 10, pp. 1372-1377, 2000.

[40] R. Doi, K. Fujimoto, M. Wada, and M. Imamura, "Surgical management of intraductal papillary mucinous tumor of the pancreas," Surgery, vol. 132, no. 1, pp. 80-85, 2002.

[41] T. Matsumoto, M. Aramaki, K. Yada et al., "Optimal management of the branch duct type intraductal papillary mucinous neoplasms of the pancreas," Journal of Clinical Gastroenterology, vol. 36, no. 3, pp. 261-265, 2003.

[42] B. S. Choi, T. K. Kim, A. Y. Kim et al., "Differential diagnosis of benign and malignant intraductal papillary mucinous tumors of the pancreas: MR cholangiopancreatography and MR angiography," Korean Journal of Radiology, vol. 4, no. 3, pp. 157-162, 2003.

[43] Y. Kitagawa, T. A. Unger, S. Taylor et al., "Mucus is a predictor of better prognosis and survival in patients with intraductal papillary mucinous tumor of the pancreas," Journal of Gastrointestinal Surgery, vol. 7, no. 1, pp. 12-18, 2003.

[44] M. Sugiyama, Y. Izumisato, N. Abe, T. Masaki, T. Mori, and Y. Atomi, "Predictive factors for malignancy in intraductal papillary-mucinous tumours of the pancreas," British Journal of Surgery, vol. 90, no. 10, pp. 1244-1249, 2003.

[45] C. P. Raut, K. R. Cleary, G. A. Staerkel et al., "Intraductal papillary mucinous neoplasms of the pancreas: effect of invasion and pancreatic margin status on recurrence and survival," Annals of Surgical Oncology, vol. 13, no. 4, pp. 582594, 2006.

[46] M. Raimondo, I. Tachibana, R. Urrutia, L. J. Burgart, and E. P. DiMagno, "Invasive cancer and survival of intraductal papillary mucinous tumors of the pancreas," American Journal of Gastroenterology, vol. 97, no. 10, pp. 2553-2558, 2002.

[47] D. E. R. Sutherland, A. C. Gruessner, A. M. Carlson et al., "Islet autotransplant outcomes after total pancreatectomy: a contrast to islet allograft outcomes," Transplantation, vol. 86, no. 12, pp. 1799-1802, 2008.

[48] S. Förster, X. Liu, U. Adam, W. D. Schareck, and U. T. Hopt, "Islet autotransplantation combined with pancreatectomy for treatment of pancreatic adenocarcinoma: a case report," Transplantation Proceedings, vol. 36, no. 4, pp. 1125-1126, 2004.

[49] F. Alsaif, M. Molinari, A. Al-Masloom, J. R. T. Lakey, T. Kin, and A. M. J. Shapiro, "Pancreatic islet autotransplantation with completion pancreatectomy in the management of uncontrolled pancreatic fistula after whipple resection for ampullary adenocarcinoma," Pancreas, vol. 32, no. 4, pp. 430431, 2006.

[50] B. W. Lee, J. H. Jee, J. S. Heo et al., "The favorable outcome of human islet transplantation in Korea: experiences of 10 autologous transplantations," Transplantation, vol. 79, no. 11, pp. 1568-1574, 2005. 
[51] S. Miyakawa, A. Horiguchi, M. Hayakawa et al., "Intraductal papillary adenocarcinoma with mucin hypersecretion and coexistent invasive ductal carcinoma of the pancreas with apparent topographic separation," Journal of Gastroenterology, vol. 31, no. 6, pp. 889-893, 1996.

[52] R. P. L. M. Hoogma, P. J. Hammond, R. Gomis et al., "Comparison of the effects of continuous subcutaneous insulin infusion (CSII) and NPH-based multiple daily insulin injections (MDI) on glycaemic control and quality of life: results of the 5-nations trial," Diabetic Medicine, vol. 23, no. 2, pp. 141-147, 2006.

[53] D. Bruttomesso, D. Crazzolara, A. Maran et al., "In Type 1 diabetic patients with good glycaemic control, blood glucose variability is lower during continuous subcutaneous insulin infusion than during multiple daily injections with insulin glargine," Diabetic Medicine, vol. 25, no. 3, pp. 326-332, 2008.

[54] "Intensive blood-glucose control with sulphonylureas or insulin compared with conventional treatment and risk of complications in patients with type 2 diabetes (UKPDS 33). UK Prospective Diabetes Study (UKPDS) Group," The Lancet, vol. 352, no. 9131, pp. 837-853, 1998. 


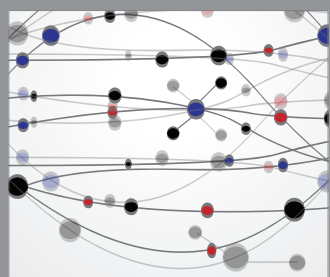

The Scientific World Journal
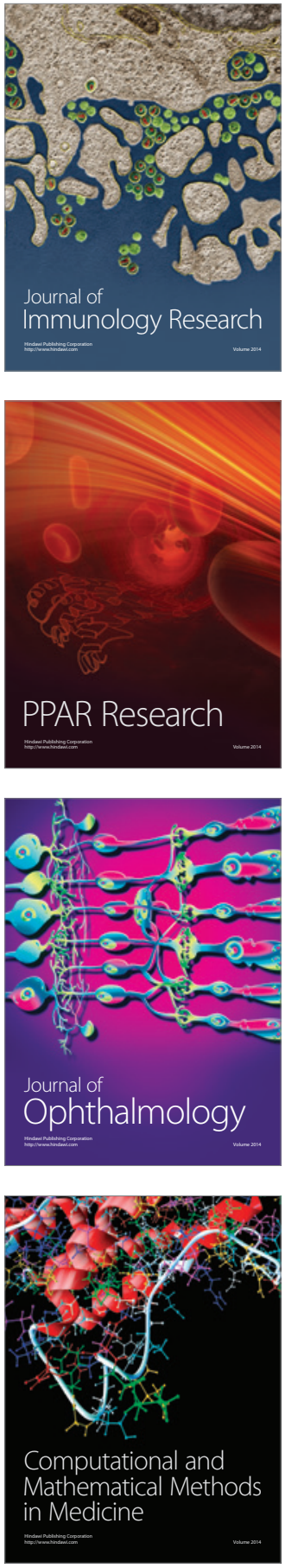

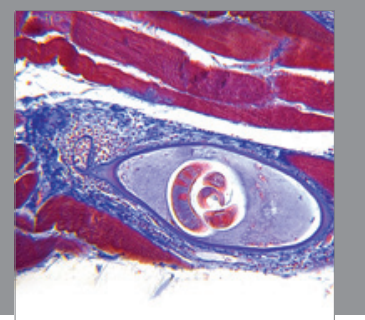

Gastroenterology

Research and Practice
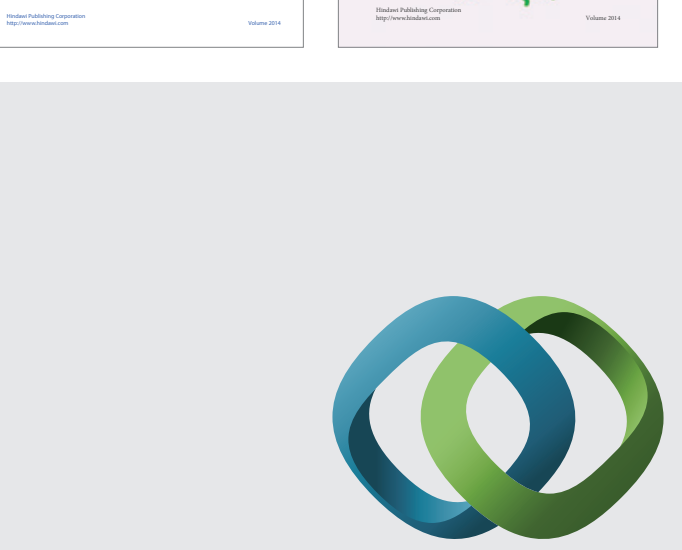

\section{Hindawi}

Submit your manuscripts at

http://www.hindawi.com
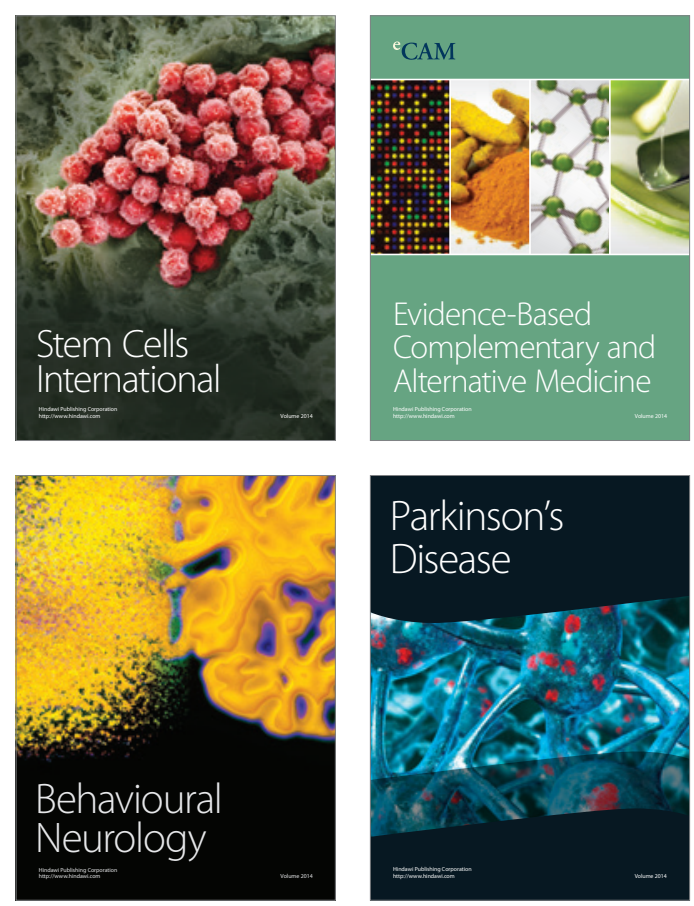

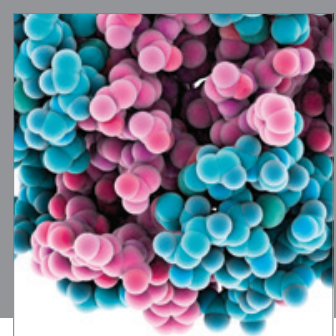

Journal of
Diabetes Research

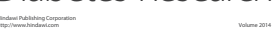

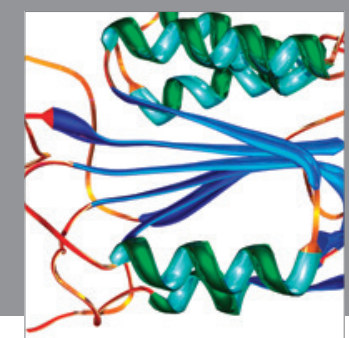

Disease Markers
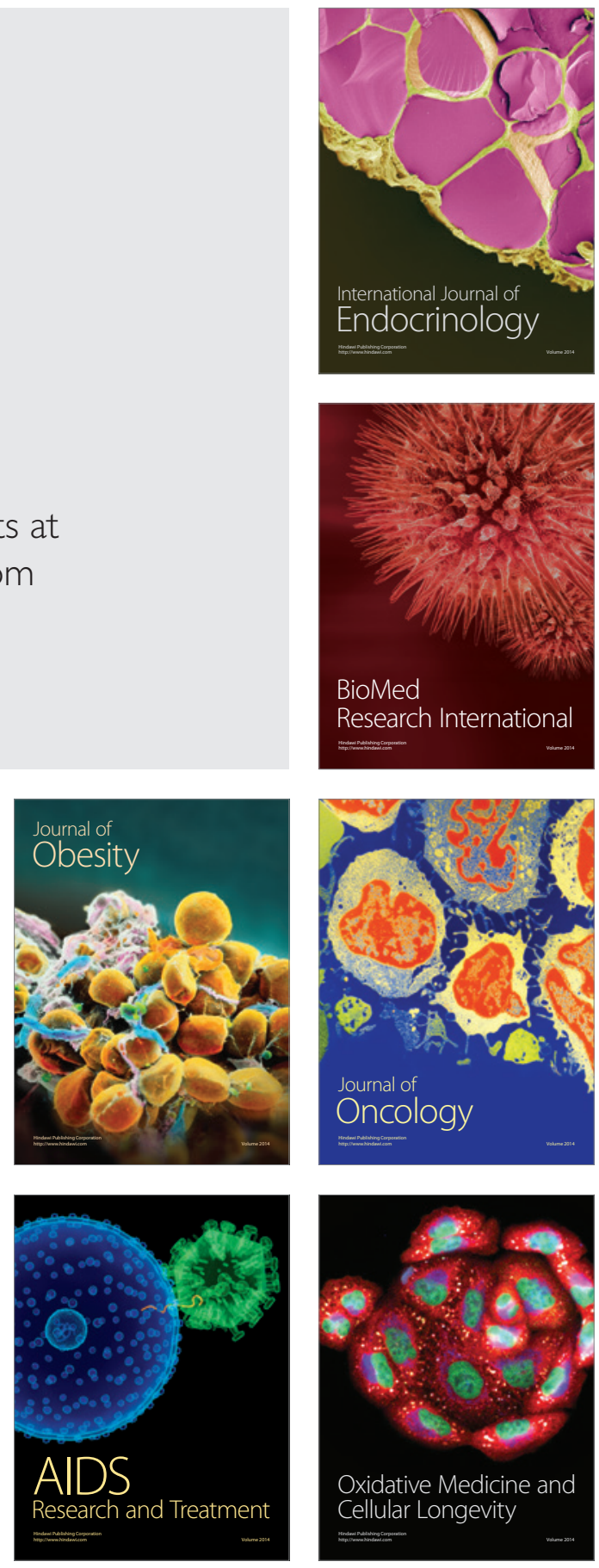